\title{
ANACRONISMOS LINGÜÍSTICOS CON CLARA INTENCIONALIDAD LITERARIA EN «NUESTRO VIRGEN DE LOS MÁRTIRES» DE TERENCI MOIX
}

\author{
JOSÉ ROMERA CASTILLO \\ (Universidad Nacional de Educación a Distancia. Madrid)
}

0. En septiembre de 1983, las prensas barcelonesas de Plaza \& Janés daban a luz pública dos obras del escritor catalán Terenci Moix. Aunque de género distinto, ambas se enmarcan temáticamente en lo que podríamos llamar literatura egiptológica por ser este legendario país el centro de sus recreaciones y/o fabulaciones. Terenci del Nilo es un libro de viajes - - el subtítulo ya se encarga de aclararlo: Viaje sentimental a Egipto - y Nuestro Virgen de los Mártires es una novela en el pleno sentido del término. De ahi que literatura de vivencias y literatura de figuración - si nos guiamos por el canon de los géneros como primera aproximación; la lectura se encargará, luego, de desvelar la fundición del autor- se complementan en interacción mutua.

Las dos obras surgen del amor-pasión por Egipto. No es nada extraño que Terenci Moix a veces diga que nació en Alejandría y que sus dos leits motivs confesables y de mayor importancia para su inspiración sean Egipto y "el joven príncipe ideado por el señor Shakespeare» (por este orden). Para ambos libros se pueden aplicar las palabras del Acaso Prólogo de Terenci del Nilo:

$\left.1 .^{\circ}\right)$ Aspiran «a convertir en literatura un profundo acto de amor. Tan profundo es, que exige la nacionalidad egipcia para mi espíritu. Literatura y amor, escapes líricos, un cierto onanismo del recuerdo, nostalgia de los siglos que no viví y constantes recorridos por mi tiempo salvaje que pasó. Noble recuerdo del egotismo que se traiciona a si mismo e intenta tender trampas al lector, si éste le deja". 
$2^{\circ} .^{\circ}$ Reiteración de "las cosas que amo de Egipto (además de amar a Egipto entero) y no sabiendo las que pudiera amar el lector -o cada uno entre los lectores - decido organizar mi estructura de acuerdo a mis placeres. Ello hará que esta estructura que emprendo sea, posiblemente, la de la insistencia».

3..$^{\circ} Y$ sobre todo un hecho muy importante, gracias a Egipto — "sólo esta palabra llena mi vida"-, tras siete años de "gratificadora holganza", "harto de una circunstancia cultural muy poco propicia para ilusionarse en la creación, enamorado de otros medios que la técnica moderna pone a disposición de la narrativa", la literatura logra recuperar a uno de sus hijos pródigos; y el escritor, a su vez, lo hace con Egipto de una manera doble, según él mismo cuenta: "Y es que mientras trabajaba en el presente vómito de mis experiencias iniciáticas [se refiere, claro a Terenci del Nilo] creaba paralelamente una ficción destinada a aparecer al mismo tiempo. Se trata de una novela titulada Nuestro Virgen de los Mártires que transcurre en la Tebaida, con retazos alejandrinos, piramidales y nilóticos. Mientras en el presente libro hablaba de Adriano y la ciudad que mandó edificar en Egipto, también inventaba para la novela el aspecto imaginario de Antinoé. Así pues, mi amor literario iba creando su propio $k a$, su doble espiritual. $Y$ el ejercicio se me ha ido revelando de una utilidad apasionante, pues me obligaba a crear dos oficios distintos partiendo de un ensueño idéntico. $Y$ a edificar mundos opuestos, lenguajes antagónicos partiendo de la repetición de algún ambiente». Auctor dixit.

Y para terminar esta introducción dos observaciones nada ajenas a 10 lingüístico:

La primera: Terenci del Nilo —de ahora- apareció en 1970, en catalán, con el título Terenci del Nil. La obra de 1983 no es una traducción de la catalana, sino algo más como el propio autor se encarga de aclarar en el Acaso Prólogo: "Publiqué a todo riesgo, y sin demasiado rigor, una primera redacción en catalán de este libro que sale hoy a la luz y que sólo conserva de entonces el título, algún fragmento disperso - para mi entrañable - y una capacidad de amor idéntica, si no ampliada. Siendo todo viaje a Egipto [y van 16, desde enero de 1968, fecha del primero] un proceso de iniciación en los misterios del Tiempo ["Muerte y Tiempo han sido las constantes permanentes de mi obra»], no es nada extraño que el vuelo de este monstruo me arrastre también a mí, y que nada o, casi nada de aquel libro joven se corresponda con mis intereses actuales [el subrayado es nuestro], con la ampliación de mis conocimientos del país que amo o la posible mejora de mis recursos para poner sobre los papeles los alcances de este amor». Aparte de esa 
re-escritura, queda una interrogante en el aire ¿por qué la primera versión en catalán y la de ahora en castellano?

La segunda observación enunciada: como es bien sabido, Terenci Moix ha escrito siempre sus novelas en catalán, aunque luego hayan sido traducidas a la lengua de Cervantes. Ahí están La torre de los vicios capitales, Olas sobre una roca desierta, El dia en que murió Marilyn, La increada conciencia de la raza, Mundo macho... hasta llegar a Nuestro Virgen de los Mártires que se convierte en la primera pieza novelística de Moix que da a luz en castellano.

En la mente de todo observador, por muy cauto que sea, surge de inmediato la pregunta: $¿$ a qué se puede deber este cambio de la lengua de Verdaguer por la de Quevedo? El hecho en si es discordante tanto por el comportamiento lingüístico del autor hasta el momento, como por vivir Cataluña hoy un vivo proceso de recuperación lingüistica nada ajeno a lo político. ¿Por qué este cambio de actitud lingüística en Terenci Moix, ahora, precisamente ahora, cuando el catalán tiene más caldo de cultivo? ¿Razones políticas, económicas o de otro matiz han sido la causa de tal deserción? Las claves, en última instancia, las tendrá el escritor, pero el crítico tiene perfecto derecho a opinar, aun con el riesgo de elucubrar o equivocarse. Terenci es un escritor heterodoxo y como tal gusta ir en dirección prohibida -a contramano como diria un castizo sevillano- o hacer su contradanza - evocando el título teatral de Francisco Ors-. Con el uso de la lengua parece seguir esta pauta. Antes, cuando el catalán estaba en los sótanos oficiales, él escribía sus novelas en la lengua sojuzgada; ahora, en esta nueva reinaxença, no exenta - como todo- de rentabilidad no sé de qué tipo, él va contracorriente, al menos por ahora. Y la causa no es otra - creo yo- que reafirmar una vez más su peculiaridad. su antigregarismo, por esa "perdida vivacidad de Barcelona" que él mismo anota. El hecho está ahí y que cada cual lo interprete desde su ladera, pero no quería dejar de reseñarlo. El «paladín de anomalías» (p. 22) se muestra una vez más.

«En esta novela - se dice en el prólogo- de ambiente histórico nada sucedió, nada es verdad, ningún personaje existió, no estuvieron decorados como en ella los ambientes. Es una chinoiserie, es una egipciería, es orientalía y es un vómito del Barroco". En efecto, Mamercus, el protagonista radial del relato, escribe desde la Tebaida, punto prestigioso de antiguo cristianismo, los recuerdos de su vida, enmarcada en la Roma de la decadencia del siglo IV. En el primer acto de la obra, que abarca los veintiséis primeros capítulos («De haber existido en mis tiempos el telón, caería en esta escena como propicio final del primer acto", p. 140), Mamercus evoca su juventud en Emporion - presen- 
cia catalana exclusivamente geográfica esbozando un cuadro donde lo ambiental, lo familiar y, sobre todo, lo personal dan vida a una realidad, aun con marco histórico, claramente fantaseada. Mamercus es un joven histrión que da vida en las tablas a vírgenes de la tragedia. De ahí que todos lo conozcan por el mote de la Casandra, su papel más importante. Allí conoce al joven actor cretense Hercos de Gortyna, enamorado a su vez de Luciano de Cnossos, convertido al cristianismo y a quien busca por doquier. Mamercus, arrastrado por su amor-pasión hacia Hercos, lo sigue en su viaje a Egipto con escala en Cartago, que es el segundo acto del libro. Paganismo, cristianismo y homosexualidad son los tres ejes semánticos que explican y desembocan en el título -y en el meollo- de la obra.

Nuestro Virgen de los Mártires. La concordancia entre el adjetivo y el sustantivo es agramatical. Desvío que sólo la lengua literaria se permite el lujo de emplear, desde un punto de vista gramatical, pero que viene a sintetizar la doble perspectiva del protagonista: en el teatro siempre hace de virgen trágica y en su realidad vital no logra satisfacer sus apetitos carnales con los cristianos que desea (Hercos, sobre todo, y el atlético anacoreta que al final lo arrebata en un carro -como a Eliseo - al desierto de la Tebaida). Virgen y mártir —-paradoja del sentido cristiano- de los mártires, que no de los paganos (Servio Potencio, el amante de su padre, lo violará en el primer acto). $\mathrm{Y}$ lo del adjetivo posesivo nuestro no es otra cosa que imán acercatorio en estas Actas del santoral del homosexualismo, que es en realidad esta novela. Literatura de militancia, en otras palabras. Desvío, en suma, tanto en la forma gramatical del título, como en la materia del contenido.

Pero sigamos con lo que nos ocupa. Se ha dicho y con razón (lo apuntaba Luis Suñén en la reseña del libro: suplemento Libros, el País, domingo 4 de diciembre de 1983 , p. 4) que Nuestro Virgen de los Mártires es "un libro divertido". Y en ciertas secuencias lo es. Humor -una de cuyas características es el contraste- que se pone de manifiesto en una serie de ocasiones gracias a lo que podríamos denominar ucronismo lingüístico. El empleo de ciertos recursos de lengua (o de lenguas) en un relato «de ambiente histórico" (el Imperio romano de la decadencia) así lo pone de manifiesto. Veamos algunos botones de muestra de estos anacronismos:

1. En el ambiente teatral que el argumento recoge - no se olvide que la novela va dedicada a Nuria Espert, maga prodigiosa: el eco calderoniano es explícito- el léxico dramático aflora por doquier: teatro (pp. 12, 16, 18, 23, 24, etc.), histrión (pp. 16, 17, 18, etc.), actor(es) (pp. 19, 96), actrices (p. 189), autor dramático (p. 25), textos (p. 156), tragedia (pp. 17, 23, 34, etc.), comedia (pp. 23, 24, etc.), drama (p. 117), 
catarsis (p. 117), escena (pp. 16, 17, 19, 26, 28, etc.), coturnos (pp. 22, 23, 24, etc.), gradas (p. 23), máscara (p. 23), coro (p. 81), compañia (pp. 24,120 ), función ( $p p .95,100,109$ ), ensayos (p. 118), representación (pp. 34, 39, 99), repertorio (p. 23), temporada (pp. 200, 214), escenarios (p. 127), luces de la escena (p. 228), escenógrafos (p. 214), estreno ( $p p$. 43-44), reestreno (p. 44), ensayar (p. 225), vestuario (p. 149), sustitución (p. 118), camerino (pp. 120, 122), palco (p. 87), público (pp. 23, 24), aplausos (p. 23), giras (p. 188) y tantos y tantos otros para terminar con la claca (p. 96). Términos que algunos cuadran con la época, pero otros son de claro matiz anacrónico.

Pero donde este fenómeno aparece con clara intencionalidad humorística es en las siguientes expresiones:

- "¿Medea convertida en la Inés del Tenorio?" (p. 181).

- "Anunciad al dómine Philipos de Abukir que llegó a la hora convenida para el almuerzo el doncel Mamercus de Emporion, actor de fama, recompensado con la Lira de Plata en el Festival de Gerundia» (p. 195).

- «...dar vida a la descarada Lisístrata - una burguesita al fin y al cabo-》(p. 23-24).

- "Padremio: dadme este papel por humillante que sea para mi rango; dadme incluso el cargo más bajo en las letrinas, mandadme barrer las gradas o acomodar a los espectadores de la general..." (p. 40).

- "Pero con el crecimiento de mis éxitos en la escena, me ocupé tanto en la memorización de papeles, lecciones de ortofonia y clases de expresión corporal...» (p. 105).

- "Antes de que toque el tercer timbre, instrúyeme sobre él" (p. 96).

Asimismo encontramos distorsiones anacrónicas en otros aspectos referidos al mundo de la canción o del espectáculo:

- Cuando Mamercus cree haber encontrado en el mercader fenicio el hombre de sus carnes, éste aparece travestido y en su danza báquica, «empezó a entonar con voz de trino el famoso cantable de la lliria:

mi jaca, galopa y corta el viento

cuando pasa por el templo..." (pp. 69-70).

- «...en la rotonda del parque de los silfos triunfó la banda municipal con una logradísima versión de la cantiga El sitio de Troya " (pp. 92-93), clara evocación del de Zaragoza.

- "Y Orfeo canta la raspa en una taberna de Sufetula" (p. 102).

- "Bebamos para celebrarlo, y que te obsequien mis niñas con 
una irreprochable ejecución de la Estudiantina portuguesa" (p. 102).

- "Y Apolo se ha apuntado de soubrette en una compañía de revistas, no sé si de Celia Gámez, no sé si de Wanda Osiris" (p. 102).

- "Como María Callas cuando pasaba de cantar Elvira a Lady Macbeth" (p. 206).

$O$, finalmente, la clara referencia a Bibi Andersen: "Luciano se llamaba. Pero ahora la soldadesca, cuando va al calabozo a escarnecerle, le llama la "Bibi»" (p. 251).

La lista de estos aspectos lingüísticos se podría alargar. Citaré, en otros ámbitos, unos ejemplos más:

- "Júpiter mismo ha puesto un sex-shop en el Olimpo.

-Y la forja de Vulcano fabrica preservativos» (p. 102).

- «Siendo mi padre la estrella máxima del teatro clásico en todos los escenarios...; ejerciendo asimismo de empresario de sus propios espectáculos... me recomendó unos pocos días de paciencia, pues quedaría vacante una de las corifeas (el actor que lo representaba, se iba de la compañía para poner una boutique de botijos en algún lugar de la Dalmacia...)" (p. 40).

- "Pues el amor, cuando es amor de veras, se complace en la discreción y no pone anuncios en las esquinas del Foro» (p. 103).

- «Ninguna ágora más propicia para que celebrasen su congreso los físicos de tres provincias" (p. 233).

- "Y por último conté hasta cinco invitados que procedían de los cuerpos diplomáticos extranjeros radicados permanentes en la ciudad" (p. 212).

- «...aquel tren de vida no tardaría en agotar mis ahorros... De ahí que aun cuando no hubiese contado con una sola piastra, hubiese fingido ser la mismísima Semíramis...” (p. 189).

- Hercos "no perdió ocasión de frecuentar la sociedad de los amigos de Saulo de Antinoé [los cristianos], y junto a ellos se dedicó a no sé qué raro turismo del dolor" (p. 184).

- "Mala cosa - dije-: es sabido que la excesiva dulzura empalaga, para no hablar de la diabetes que provoca» (p. 112).

$Y$, por último, la evocación del anuncio en ciertas revistas rosas: "¿Busca acaso adolescente solitario, bien dispuesto, culto y trabajador?» (p. 97).

2. Anacronismos lingüísticos encontramos también en la apelación a ciertos personajes, empleando tratamientos en diversas lenguas: griego, francés, inglés, etc. Veamos algunos ejemplos: 
- El portero de la casa de Philipos llama a Mamercus en tres ocasiones con el término griego Kyrios (señor) (pp. 207-208).

- El dominus latino, castellanizado en dómine, se aplica a Philipos de Abukir (p. 195).

- Los términos franceses, adaptados a la fonética y escritura española, madama (pp. 61, 74, 75, 92, 100, 139, 191) y mesiés (p. 139).

- El tratamiento inglés de lord lo reciben tanto Mamercus (p. 175) como Agro Numudio (pp. 175, 178, 181, 183).

- Además del arcaísmo castellano de vuesas mercedes con el que Mamercus se dirige a su padre, Livio de Nivea, y al centurión, Servio Potencio (p. 86). Nombres de claro matiz irónico.

3. Ya que hablamos de arcaísmos conviene examinar los castellanos que aparecen tanto en léxico como en expresiones, que a la vez que tienen una función ucrónico-humorística, sirven también para proporcionar cierto rancior a la escritura.

- Encontramos sintagmas compuestos por artículo + posesivo + nombre de clara raíz medieval: "Aclara, el mi hijo, esta tu acusación" (p. 40); "Y esto supe también por el mi padre» (p. 146); "...sangrando las sus partes" (p. 106).

- Expresiones como: «de esta guisa» (p. 205); "doquiera" (p. 123); "Su venia" (p. 44); etc... Y términos como: físico (por médico) (pp. 107, 243); cuitas (pp. 65, 97, 148, 173); vulgo (pp. 91, 92, 94, 117); etc.

- Asimismo Mamercus usa el tratamiento vos para dirigirse a su madre (p. 45), a su padre (p. 55), a Eunice (p. 73) O a Agro Numidio (p. 178-179).

Por contraposición a este rancio lenguaje encontramos términos de clara raigambre pasota: "Búsquense las señoras satisfación a su movida, que la mía no quiere pleitos» (p. 99); «...se arrojaron flores a los pies de los soldados, que desfilaron marchosos como nunca" (p. 92); etc. O algún americanismo como papaya (pp. 102, 107) para designar, no el fruto tropical, sino el órgano sexual femenino como se hace, por ejemplo, en Cuba. O la clara expresión del cono Sur americano: "Contame, viejo" (p. 97).

4. Anacrónico también es el empleo del francés, el inglés y otras lenguas en ciertos pasajes, sin que aparezca nunca el catalán, la lengua vernácula del escritor.

Francés:

a) argent de poche (p. 40).

b) Helas! (p. 123). 
c) et pour cause (p. 188).

d) "aquel famoso manjar que denominan Coquille Venerea" (p. 198).

e) Aquellos versos de Eurípides, puestos en boca de Clitemnestra, en la célebre versión francesa

"Oh monstre, que Mégère en ses flancs a porté!

Monstre, que dans nos bras les enfers ont jeté!

Quoi? Tu ne mourras point? Quoi? Pour punir son crime...

Mais oú va ma doleur chercher une victime...?» (p. 119).

Además de palabras como restaurant (pp. 189, 192), champagne ( $p$. 229), soubrette (p. 102), etc.

Inglés:

a) "Y cuando recostaba la cabeza en el poderoso hombro de $\mathrm{mi}$ primer macho, empezó él a decirme groserías. $Y$ con tal fuego las repitió varias veces, que exclamé I beg your pardon con pésimo acento (tan difícil de pronunciar es el fenicio) [claro rasgo irónico]. Y... pregunté qué pretendía en realidad de mí.

- I want to perform just for you, my cyclope - me dijo, dando un toque libidinoso a sus labios de pasa.

- What on hell are you supposed to perform, lusty male?

- Just you wait -dijo» (p. 67).

b) El antiguo palacio de Cleopatra en Alejandría, «a cuya entrada se había añadido un cartel en latín que decia: "Anthony and Cleopatra Rest House»" (p. 192).

c) Cuando Mamercus se dirige al club —otro término inglés- privado de la Secta de Onanos, un esclavo le dice: "Members only" (p. 196).

Además de palabras como dandy (p. 203) sex-shop (p. 102), etc.

El italiano tampoco está ausente en términos como atrezzo ( $p .124)$, crescendo (p. 123), loggia (p. 195), una Pietà. (p. 207), fontana (p. 243), coccine/le (p. 251). O en la cita del célebre verso puesto en boca de la madre de Mamercus cuando lo incita a penetrar en sus entrañas: "hunde en ellas tu lengua y prodúceme el dolce fremito che la belleza infiora" (p. 48).

Tampoco el griego queda fuera del texto. "Y esos jóvenes recibirán, en adelante, el título de Kleynós, que en vuestra jerga latina significa ilustre» (p. 111); "Cierto que los doctos supieron aplaudir un diálogo que ya es indiscutible, pero el pathos se perdió al fiarlo todo en el hechizo de la palabra" (p. 214); "¡Qué procesión de gnomos!" (p. 220); "Pero las manazas del macho me arrancaron la toga de un solo golpe, y apareció este mi cuerpecito, recipiente de dulzuras, cofrecillo de primores, leykós de delicadezas y anforilla de delicias" (p. 80).

El latín también hace acto de presencia. Trivium (p. 160), impluvium 
(p. 79), summun -sic- (p. 90), Caput Mundi (p. 147), turris eburnea (p. 44), etc.

5. Tampoco son ajenos a este sabor divertido el empleo de elementos léxicos de claro sabor coloquial hoy en día. Palique (p. 28), verborrea (p. 83), peroratas (pp. 25-28), mejunges (p. 26), condumio (p. 199), fanfarrias (p. 81), cuchitriles (p. 127), cachivaches (p. 92), artilugios (p. 28), forofos (p. 161), pelmazo (p. 210), frescachón (p. 139), cotilleo (p. 92), cotillas (pp. 101-190), macha (p. 93), machota (p. 107), guarra (p. 100), gaznate (p. 85)... y tantos otros posibles de señalar. Así como también expresiones como: toca $y$ daca (p. 87), dimes y diretes (p. 92), tira y afloja (p. 114), etc. O la anteposición del artículo a nombres famosos como: la Medea (p. 74), la Metella (p. 182), etc.

6. En síntesis - y termino- estos botones de muestra -en modo alguno exhaustivos - proporcionan al relato un matiz irónico-humorístico y, sobre todo al ser empleados de una forma consciente por el creador, adquieren una relevancia artística al insertarlos en otro sistema peculiar: el de la lengua literaria. Pero eso sí, no olvidando el lema con el que Terenci Moix define su escritura: "En lugar de seguir las reglas doradas de los grandes autores, quebranto todas las leyes de la unidad y vuela mi estilete al ritmo alocado que decretan mis nostalgias". Dicho y hecho. 